\section{La Révolution française}

Cahiers de l'Institut d'histoire de la Révolution française

9 | 2015

Citoyenneté, république, démocratie dans la France de la Révolution

\title{
La longue genèse de la citoyenneté dans le second Empire colonial 1798-1898
}

\section{Yerri Urban}

\section{(2) OpenEdition}

\section{Journals}

Édition électronique

URL : http://journals.openedition.org/lrf/1460

DOI : $10.4000 /$ Irf. 7460

ISSN : 2105-2557

Éditeur

IHMC - Institut d'histoire moderne et contemporaine (UMR 8066)

Référence électronique

Yerri Urban, "La longue genèse de la citoyenneté dans le second Empire colonial 1798-1898 », La Révolution française [En ligne], 9 | 2015, mis en ligne le 16 novembre 2015, consulté le 19 avril 2019. URL : http://journals.openedition.org//rf/1460 ; DOI : 10.4000/Irf.1460

Ce document a été généré automatiquement le 19 avril 2019

(c) La Révolution française 


\title{
La longue genèse de la citoyenneté dans le second Empire colonial
} 1798-1898

\author{
Yerri Urban
}

Cette recherche a été possible grâce au soutien financier apporté par le LABEX CEBA (projet ABIOS del'Agence Nationale de la Recherche (CEBA, ref. ANR-10-LABX-25-01).

1 Lorsqu'il connaît son apogée territoriale, dans l'entre-deux guerres, l'Empire ${ }^{1}$ colonial français est doté d'une citoyenneté fragmentée ${ }^{2}$. Suffrage universel, suffrage restreint, «représentation des intérêts ", nomination, absence de représentation politique sur le territoire colonial: de multiples formes de hiérarchisation divisent aussi bien les indigènes que les Français. Mais, quant aux modalités de cette fragmentation, le pouvoir métropolitain n'innove pas. Durant l'entre-deux guerres, le colonisateur puise avant tout dans un répertoire de formes et de techniques juridiques élaborées auparavant, durant un siècle, entre 1798, lorsque la Ière République conçoit une forme de citoyenneté française spécifique pour ses départements coloniaux tout en partant à la conquête de l'Egypte, et 1898, lorsque la III $^{\mathrm{e}}$ République conçoit une autre forme de citoyenneté française spécifique pour ses départements coloniaux d'Algérie en créant les délégations financières. De fait, il y a bel et bien une conjonction entre colonies départementalisées (et non pas colonies transformées en départements à statut particulier comme en 1946) et différenciation en terme de citoyenneté et de nationalité. Le sens de la départementalisation n'est toutefois pas le même selon les cas: en 1795, elle est une conséquence de la première abolition de l'esclavage, en 1848, il s'agit de rattacher plus fermement les zones de peuplement européen de l'Algérie à la métropole.

2 C'est grâce au Cours de législation coloniale professé à la Libération par un des grands maîtres de la discipline, Pierre Lampué ${ }^{3}$, véritable bilan théorique du droit de l'Empire colonial de la III ${ }^{e}$ République, que l'on peut se faire une idée plus précise de la citoyenneté dans le second Empire colonial à son apogée. 
3 S'agissant de la définition de la citoyenneté, Lampué distingue une conception dans laquelle « le citoyen [...], c'est [...] la personne qui exerce des droits politiques », sens que l'on retiendra ici, et une autre conception, qui a sa préférence, dont il donne la définition suivante : «La citoyenneté est la soumission à un certain statut, qui est à la fois un statut de droit public et un statut de droit privé, qui est celui des habitants de la métropole ou qui en est du moins très voisin ${ }^{4}$. " C'est bien sûr le modèle romain que Lampué a en tête en donnant cette définition ${ }^{5}$, et c'est dans ce sens que l'on parle souvent de citoyenneté dans l'Empire colonial français. Pour Lampué, ce qui caractérise l'Empire colonial ${ }^{6}$, c'est la différence de statut juridique entre la métropole et la colonie, différence qui est aussi une inégalité : « si celui de la métropole est le statut normal et de droit commun, le statut de la colonie apparait comme un statut d'exception, un statut différent ne comportant pas les mêmes garanties que le premier. En effet, [...] le droit de cité existant dans la métropole, le status civitatis est [...] plus complet et donne plus de garantie que le droit de cité colonial.» Ainsi, la «désignation des gouvernants de l'Etat ou de l'Empire (gouvernants qui sont ceux des colonies en même temps que ceux de la métropole) est réservée aux habitants de la métropole » de manière quasi-exclusive : seuls parmi les territoires conquis après 1830, l'Algérie et la Cochinchine envoient des représentants au parlement. Quand le droit de suffrage existe dans les colonies, il est souvent réservé aux originaires de la métropole, et à ceux qui y sont assimilés ; il peut voir sa portée limitée à la seule "désignation de certains corps d'administration locaux » sans pouvoir jouer "pour la désignation des gouvernants de l'Empire, pour les organes constitutionnels. » Les libertés publiques sont plus étendues dans la métropole que dans les colonies.

4 Mais ces différences de statuts peuvent s'atténuer. Ainsi, en Guadeloupe, en Martinique et à la Réunion, le droit de cité colonial ressemble tellement à celui de la métropole que l'on envisage de transformer ces colonies en départements.

5 Dans ces territoires, il y a unité de statut : comme en métropole, on y est soit Français, soit étranger. Ailleurs, domine une conception différenciée de la nationalité : on y est soit Français, soit étranger, soit indigène ${ }^{7}$ et, parfois, notamment en Indochine et en Afrique noire, on peut également être étranger assimilé à l'indigène. En effet, dans un Empire colonial, le droit de la nationalité peut refléter, de manière plus ou moins systématique, la hiérarchie entre la métropole et ses possessions: la nationalité de la métropole sera forcément supérieure aux nationalités des possessions. Dans l'Empire français, on distingue ainsi le Français et l'indigène, lequel peut être sujet français, s'il est originaire d'un territoire français, protégé français, s'il est originaire d'un protectorat, ou administr é, s'il est originaire d'un territoire sous mandat B de la SDN. De fait, à son apogée, la domination impériale française prend des formes territoriales multiples. Il y a deux types de territoires français : l'Algérie et les colonies; et deux types de territoires relevant en principe du droit international : le protectorat et les territoires sous mandats de la SDN.

6 Parmi les territoires français, seuls ceux conquis après 1830, ceux qui n'ont pas eu une vocation esclavagiste, sont dotés d'indigènes. En principe chaque qualité d'indigène d'un territoire particulier est définie d'une manière propre : l'indigène est comme le national de sa colonie d'origine au sein de l'Empire colonial, mais est considéré comme Français dès qu'il le quitte. Autrement dit, dans les territoires annexés, les indigènes n'ont la nationalité française qu'au regard du seul droit international public, parce qu'ils sont entrés dans l'orbite de la domination impériale française. Par contre, dans les territoires dont l'existence internationale est mise en sommeil (protectorats et mandats B), les indigènes protégés et administrés ont au minimum une forme d'appartenance territoriale 
reconnue par le droit international public tout en bénéficiant de la protection diplomatique et consulaire de la France.

7 C'est en Algérie que l'indigène comme catégorie du droit de la nationalité apparaît. Dès le commencement, on considère que l'indigène n'est pas Français, ne relève pas des dispositions relatives à la nationalité française d'origine contenues alors dans le code civil, sans être par ailleurs étranger. Dans les pays musulmans, il peut bénéficier de la protection diplomatique et consulaire française en justifiant de sa "nationalité algérienne ». Les principes du droit de la nationalité des indigènes sont posés par le sénatus-consulte du 14 juillet 1865 , sur lequel je reviendrai : expression d'un compromis entre mission civilisatrice et principe des nationalités, il doit en principe permettre à l'indigène de s'assimiler à la nation française par le biais d'une naturalisation, conçue comme une « conversion à la civilisation ». L'indigène jouit à titre subsidiaire des droits des Français, c'est à dire en l'absence de dispositions qui lui sont propres. Il n'est pas pleinement citoyen français. Ces principes seront adoptés par la suite, en tout ou partie, dans les autres possessions.

8 Alors qu'en métropole ou dans les anciennes colonies esclavagistes, le Français est supérieur à l'étranger, dans les nouvelles possession coloniales, l'indigène est inférieur au Français, mais aussi, bien souvent, à l'étranger, surtout s'il est « européen »; par contre, notamment en Indochine et en Afrique noire, l'indigène est en principe supérieur à l'étranger assimilé à l'indigène qui, quant à lui, ne relève pas d'un droit regardé comme civilisé. En effet, du milieu du XIX ${ }^{\mathrm{e}}$ siècle à 1945, le droit international public est organisé autour de la notion de civilisation, entendue comme la soumission à un droit occidental. Il existe en conséquence une hiérarchie des entités politiques, une hiérarchie des peuples : au sommet, les Etats civilisés, en dessous, les Etats semi-civilisés, et tout en bas, les peuples sauvages, qui sont censés ne pas être doté de véritable organisation politique. Cette civilisation est la justification contraignante de l'inégalité qui domine dans le monde colonial : elle légitime, d'une part, diverses modalités de domination et d'annexion en droit international public et, d'autre part, le despotisme, conçu comme provisoire, du colonisateur français.

Dans le second Empire colonial à son apogée, la citoyenneté a ainsi trois caractéristiques essentielles :

- elle est fragmentée par diverses formes de hiérarchisation ;

- elle est réservée aux seuls ressortissants de l'Empire colonial, les Français et les indigènes ;

- elle est marquée par l'idée de civilisation.

Cette situation ne va pas de soi. Comment a-t-elle été possible?

Il aura fallu que colonisation, civilisation et citoyenneté puissent s'associer, puis qu'une citoyenneté pour les Français, les étrangers et les indigènes, après avoir été expérimentée, soit abandonnée. C'est alors que l'on assistera à l'invention de formes de hiérarchisation. Si, entre 1798 et 1801, apparait l'idée d'une citoyenneté pour civiliser (I) ; si, de 1847 à 1870, se développe une citoyenneté pour les résidents, qu'ils soient Français, étrangers ou indigènes (II), c'est de 1870 à 1898 que se met véritablement en place une citoyenneté pour les seuls ressortissants de l'Empire colonial, Français et indigènes (III). 


\section{Une citoyenneté pour civiliser 1798-1801}

11 C'est sous le Directoire, dans la foulée du coup d'état du 18 fructidor an V (4 septembre 1797), que l'on voit pour la première fois associées civilisation, citoyenneté et nationalité, dans le cadre de dispositions spécifiques aux colonies départementalisées. Toutefois, cette citoyenneté est conçue comme une confirmation de la première abolition de l'esclavage. L'idée d'un nouvel Empire colonial, d'une «colonisation nouvelle » n'en sera pas moins expérimentée : on envisage également de civiliser les Egyptiens et les Indiens de Guyane.

Toutefois, «entre 1795 et 1802, l'idée de civilisation est encore pensée comme un processus dynamique ${ }^{8}$. " $\mathrm{Si}$ « les rédacteurs de la constitution de l'an III redéfinissent le projet républicain en réaffirmant le partage entre une élite civilisatrice et un peuple à civiliser. Ce partage, qui légitime indiscutablement la domination de ceux-là même qui s'érigent en détenteurs des bons usages de la Raison, est néanmoins considéré comme temporaire : le projet pédagogique sur lequel repose l'entreprise de républicanisation des esprits doit en effet permettre de diminuer, voire de supprimer, à plus ou moins longue échéance, la distinction entre les élites raisonnables et le peuple ignorant et passionné. Pour le moment néanmoins, il s'agit bien de promouvoir les règles de la Raison pour justifier la dépolitisation provisoire des catégories populaires ${ }^{9}[. .$.$] . » Cette conception a$ aussi des conséquences quant aux relations avec les autres peuples, notamment avec la « mission civilisatrice » effectuée par la « Grande Nation », en Europe ou ailleurs : « Dans la droite ligne du discours légitimant la constitution de l'an III, la diplomatie du Directoire s'enracine ainsi dans le cadre d'une " histoire philosophique de l'humanité » qui stipule une similitude entre le regard porté sur les catégories populaires et celui porté sur les populations situées hors de France. [...] Pour être possibles, les progrès de la civilisation devront s'appuyer sur les relations établies par une société, un peuple ou une nation avec une entité plus évoluée et civilisée. Le "commerce ", considéré ici comme l'ensemble des échanges qu'une nation entretient avec les autres, est ainsi défini comme le moteur de la civilisation. "[...] Cette entreprise, qui ne peut être que graduelle, progressive et modérée, justifie la volonté, apparemment paradoxale, de défendre une « républicanisation sans révolution ${ }^{10}$. »

13 C'est avec ces conceptions que le Directoire va essayer d'élaborer une citoyenneté pour les nouveaux libres tout en s'efforçant de trouver des moyens d'y initier les Egyptiens et les Amérindiens de Guyane.

\section{A. Quelle citoyenneté pour les nouveaux libres?}

La loi du 12 nivôse an VI ( $1^{\mathrm{er}}$ janvier 1798) sur l'organisation constitutionnelle dans les colonies $^{11}$ est une réaction républicaine à la tendance à la restauration de l'ordre colonial traditionnel qui s'était manifestée au printemps et à l'été 1797 . Le coup d'état de fructidor, le 4 septembre, aboutit à l'exclusion et parfois à la déportation des partisans de la restauration coloniale, au renforcement du parti abolitionniste et à l'admission de plusieurs députés noirs ou de couleur. Le texte contient notamment une séries de dispositions relatives à la citoyenneté, qui tentent d'articuler le décret du 16 pluviôse an II (4 février 1794) et la constitution de l'an III (1795). 
qui tranforme en son article II les nouveax affanchis en citoyens il sagt ici de reconnaître la qualité de citoyen à tous ceux qui sont domiciliés dans les colonies, quel que soit leur statut antérieur: «Européens, Créoles, Africains, ne connaissent plus aujourd'hui d'autres couleurs, d'autre nom que ceux de Français. » déclarait le député de Saint-Domingue Louis-Pierre Dufay en conclusion de son grand discours demandant l'abolition générale. Assez paradoxalement, le texte est beaucoup plus proche de la définition de la citoyenneté donnée dans le projet de constitution girondin présenté les 15 et 16 février 1793 que des dispositions de la constitution du 24 juin 1793.

La constitution du 5 fructidor an III (22 août 1795) développe quant à elle une singulière conception de la citoyenneté. En voici les dispositions principales ou essentielles quant à la compréhension de la loi du $1^{\text {er }}$ janvier 1798 :

Art. 8 : Tout homme né et résidant en France, qui, âgé de vingt et un ans accomplis, s'est fait inscrire sur le registre civique de son canton, qui a demeuré depuis pendant une année sur le territoire de la République, et qui paie une contribution directe, foncière ou personnelle, est citoyen français.

Art. 9: Sont citoyens, sans aucune condition de contribution, les Français qui auront fait une ou plusieurs campagnes pour l'établissement de la République.

Art. 10: L'étranger devient citoyen français, lorsque après avoir atteint l'âge de vingt et un ans accomplis, et avoir déclaré l'intention de se fixer en France, il y a résidé pendant sept années consécutives, pourvu qu'il y paie une contribution directe, et qu'en outre il y possède une propriété foncière, ou un établissement d'agriculture ou de commerce, ou qu'il y ait épousé une femme française. [...]

Art. 16. : Les jeunes gens ne peuvent être inscrits sur le registre civique, s'ils ne prouvent qu'ils savent lire et écrire, et exercer une profession mécanique. Les opérations manuelles de l'agriculture appartiennent aux professions mécaniques. - Cet article n'aura d'exécution qu'à compter de l'an XII de la République. [...]

Art. 304.: Tout individu qui, n'étant pas dans le cas des articles 12 et 13 de la Constitution, n'a pas été compris au rôle des contributions directes, a le droit de se présenter à l'administration municipale de sa commune, et de s'y inscrire pour une contribution personnelle égale à la valeur locale de trois journées de travail agricole.

Art. 305. : L'inscription mentionnée dans l'article précédent ne peut se faire que durant le mois de messidor de chaque année.

18 Au-delà de ce qui relève de la définition de qui est Français (ceux qui sont nés et résident en France) et de qui devient Français (les étrangers qui notamment déclarent l'intention de se fixer en France et résident en France depuis 7 ans), la citoyenneté de l'an III ne se réduit pas à une simple restauration du système censitaire de la constitution de 1791 : il est possible d'«acheter » sa citoyenneté si l'on n'est soumis à aucune contribution directe, et l'on est dispensé de toute contribution si l'on a combattu pour la République. De plus, à partir de l'an XII (septembre 1803-août 1804), les jeunes gens devront aussi prouver qu'ils savent lire, écrire et exercent une profession mécanique: on exige désormais un "capital intellectuel minimum », un «cens culturel» (voir Jean-Luc Chappey $\left.{ }^{13}\right)$. La citoyenneté « doit faire l'objet d'un apprentissage qui ne peut se faire que dans la durée, constatation justifiant le fait que l'introduction du «cens culturel » soit 
finalement mise en suspens pendant une période de 10 ans, période pendant laquelle il s'agit de permettre au plus grand nombre d'apprendre à lire et à écrire ${ }^{14}$. »

Quant à l'application de cette citoyenneté aux colonies départementalisées par la constitution, le rapport de Boissy d'Anglas ${ }^{15}$ ne laisse guère de doute: "L'état des citoyens est réglé par la constitution même, et vous n'y apporterez aucune exception : s'il est permis d'en appliquer à des dispositions législatives, ce ne peut être qu'en faveur de la liberté des hommes. L'abolition de l'esclavage a été solennellement décrétée, et vous ne voudrez point la modifier; c'est une conséquence de vos principes, un des résultats de votre révolution, et vous ne pouviez-vous dispenser de les proclamer avec éclat; c'est le seul acte de justice que la tyrannie vous ait enlevé; vous ne voudrez pas, sans doute, paraître moins attachés qu'elle à ces principes éternels qu'elle a su si peu respecter. Rendre à tous les habitants des colonies indistinctement cette liberté qu'on n'avait pu leur ravir que par la violence et par la force, c'est en faire non seulement des hommes libres, mais encore des citoyens. L'exercice des droits politiques ne sera donc déterminé que par les lois constitutionnelles que vous avez déjà décrétées. »

De fait, l'esclavage n'est pas compatible avec la constitution de l'an III : la déclaration des droits et des devoirs de l'homme et du citoyen précise, en son article 15 : «Tout homme peut engager son temps et ses services; mais il ne peut se vendre ni être vendu; sa personne n'est pas une propriété aliénable.» Le caractère contraignant de cette disposition est confirmé par l'article 352 de la constitution : « La loi ne reconnaît ni vœux religieux, ni aucun engagement ${ }^{16}$ contraire aux droits naturels de l'homme. »

21 Mais si, dans le discours de Boissy, l'application dans les colonies départementalisées des dispositions relatives à la citoyenneté est une manière de garantir l'abolition, certains problèmes pratiques, tels que l'absence d'état-civil, les modalités de l'abolition dans les colonies conquises ou reconquises après le décret du 16 pluviôse, le statut des esclaves affranchis par le sol français, évadés de colonies étrangères ou issus de négriers arraisonnés, peuvent difficilement être réglés à l'aide des seules dispositions constitutionnelles. Faut-il traiter tous les affranchis comme de nouveaux citoyens, ce qu'ils sont automatiquement depuis la loi des 28 mars et 4 avril 1792, ou au contraire faire comme s'ils avaient été libres dès leur naissance, leur appliquer les dispositions relatives à la citoyenneté et donc, en l'occurrence, étant donné l'imbrication entre les deux notions dans la constitution de l'an III, à la nationalité. Dans cette seconde hypothèse, il y a forcément un clivage entre les esclaves créoles, nés dans la colonie, et les esclaves africains, qui sont nés en Afrique. Enfin, dès la proclamation de Sonthonax, les nouveaux libres ont vu leur situation régie par des règlements de cultures, qui leur accordent une rémunération tout en les maintenant dans la plantation. Comment articuler cette situation à la citoyenneté ? La loi du $1^{\text {er }}$ janvier 1798 s'efforce de régler ces questions selon les modalités suivantes :

Titre III : De l'état et des droits des citoyens

Art. 14: La déclaration de quatre citoyens de la commune suffira pour constater l'âge des individus dont la naissance n'est pas consignée dans les registres publics servant à constater l'état des citoyens; cette déclaration sera insérée sur les registres : l'inscription tiendra lieu d'extrait de naissance.

Art. 15 : Les individus noirs ou de couleur enlevés à leur patrie, et transportés dans les colonies, ne sont point réputés étrangers ; ils jouissent des mêmes droits qu'un individu né sur le territoire français, s'ils sont attachés à la culture, s'ils servent dans les armées, s'ils exercent une profession ou métier. 
Art. 16: Tout individu convaincu de vagabondage par un tribunal correctionnel, sera privé des droits accordés par l'article précédent, jusqu'à ce qu'il ait repris la culture, un métier ou une profession.

Art. 17 : Sera réputé vagabond tout individu qui ne pourra justifier d'un domicile et d'un état connus.

Art. 18 : Tout individu noir, né en Afrique ou dans les colonies étrangères, transféré dans les îles françaises, sera libre, dès qu'il aura mis le pied sur le territoire de la République : pour acquérir le droit de citoyen, il sera, pour l'avenir, assujetti aux conditions prescrites par l'article 10 de l'acte constitutionnel.

Art. 19: Tout citoyen qui voudra jouir du droit de voter dans les Assemblées primaires pour la première année de l'organisation constitutionnelle déclarera, lors de la formation du tableau de population ordonné par l'article 12 de la présente loi, qu'il veut payer une contribution personnelle égale à trois journées de travail agricole: il sera tenu, sous peine d'être privé de son droit de suffrage, d'en présenter la quittance dix jours au moins avant la tenue des Assemblées primaires.

A l'avenir, nul citoyen ne sera dispensé de se conformer à l'article 305 de la Constitution.

Art. 20: Il suffira également, pour jouir de l'avantage porté par l' article 9 de la Constitution, de rapporter à l'administration municipale, dix jours avant la tenue des Assemblées primaires, un certificat du Conseil d'Administration qui attestera qu'on a fait, pendant la Révolution, une ou plusieurs campagnes contre les ennemis de la République.

Le projet initial du titre III présenté par Joseph Eschassériaux devant le Conseil des CinqCents $^{17}$ diffère assez sensiblement, sans que l'on en connaisse les raisons, de la résolution soumise au Conseil des anciens ${ }^{18}$, qui sera adoptée en l'état après avoir concentré une partie des débats. Si la rédaction des dispositions ne change guère (la plus importante consistant à remplacer, dans l'article 15, le terme « Africain » par celui d' « individu noir ou de couleur »), deux articles sont ajoutés : l'article 17 et surtout l'article 18, qui modifie considérablement l'économie du projet initial. En effet, il scinde les Africains en deux catégories distinctes et ajoute les esclaves créoles des colonies étrangères. Les débats seront focalisés sur les articles 17 , surtout, et 18 .

L'opinion de Dufay, à nouveau député de Saint-Domingue ${ }^{19}$, est essentielle pour comprendre l'articulation de la loi du $1^{\mathrm{er}}$ janvier 1798 avec le décret du 16 pluviôse an II, dont elle est à la fois la confirmation et le recommencement : l'article 31 n'affirme-t-il pas, de manière symbolique, que tous les textes « contenant des principes contraires à la constitution et au décret du 16 pluviôse an II sont abrogés et anéantis pour toujours. » Il est, en effet, le seul à constater que le projet est en rupture avec le décret d'abolition quant à aux dispositions relatives à la citoyenneté : «Demander que les noirs enlevés à leur patrie ne soient pas réputés étrangers, et jouissent des mêmes droits que les individus, que les noirs, leurs frères, et leurs compagnons de culture nés sur le territoire français, c'est mettre en question s'ils jouissent tous, ou doivent jouir tous de la plénitude des droits assurés par la constitution ; c'est faire deux classes d'hommes parmi ces noirs, qui sont tous libres du même jour, qui ont tous également combattu pour la défense de Saint-Domingue et le maintien de la République [...].» Les critiques de Dufay sont toutefois plus ambigües qu'il n'y paraît au premier abord : s'il souhaite « une rédaction précise, simple et claire, qui embrassât la généralité des citoyens, sans aucune distinction, et dans les mêmes termes que le décret du 16 pluviôse ", il veut y ajouter la fin de l'article 15 (« s'ils sont attachés à la culture [...]»), ce qui revient à appliquer à « tous les hommes, sans distinction de couleur, domiciliés dans les colonies » des dispositions restrictives qui ne devaient s'appliquer qu'à une partie des anciens esclaves nés en Afrique. 

première fois, dans l'ordre civil, et dont les éléments doivent être arrangés avec harmonie dans la constitution. Vous êtes à leur égard un législateur constituant qui a à faire des citoyens avec des hommes. » : c'est ainsi qu'Eschasseriaux présente le projet de titre III ${ }^{20}$. Dans un style plus sobre, Roger-Ducos présente ainsi l'article $15^{21}:$ « Les individus noirs ou de couleur enlevés à leur patrie, et transportés dans les colonies, ne sont point réputés étrangers; ils jouissent des mêmes droits qu'un individu né sur le territoire français; mais il fallait des conditions utilement prévoyantes dans une République où la vraie liberté est inséparable des devoirs que tout homme qui s'y réunit doit être obligé, doit être jaloux d'y remplir. Ces conditions font que les noirs jouissent des droits de citoyen français, s'ils sont attachés à la culture, s'ils servent dans les armées, s'ils exercent une profession ou un métier. Et ici se développe le grand acte politique qui lui permet de tourner au profit et de la société et des membres qui la composent, en ramenant par ces moyens ces hommes égarés, trop désespérés peut-être, au travail où les rappelle la voix de la liberté. Non, les hommes de couleur ne sont plus étrangers parmi nous; mais ils doivent rentrer dans l'ordre, se soumettre aux lois communes, s'attacher à la culture, servir la patrie, exercer un état ou une profession, vivre en un mot de leur travail. Celui qui répugne à remplir quelqu'un de ces devoirs ne serait point Français; il ne mériterait pas de fouler le sol de la liberté ; ce ne serait qu'un vagabond sans patrie ; il devrait être poursuivi et traité comme tel. »

Roger-Ducos insiste sur les articles 16 et 17 qui privent les vagabonds des droits reconnus par l'article 15, jusqu'à ce qu'ils aient repris une activité. Il précise que cette disposition n'empêche pas que les lois sur le vagabondage s'appliquent également aux intéressés. L'extrême originalité de la peine prévue par l'article 16 est qu'il ne s'agit en rien d'une peine d'indignité mais d'une privation de la qualité de Français qui cesse dès qu'une activité est reprise: le but de la disposition est de toute évidence de maintenir les nouveaux libres africains dans les plantations. Est ainsi créé un statut hybride de nouveau libre africain presque Français : beaucoup parmi eux ne pourront être citoyens que s'il renoncent à une partie de leur liberté en demeurant rattachés à une plantation ${ }^{22}$. Mais cette situation est justifiée par cette dérogation à l'article 8 de la constitution de l'an III qu'est l'article 15 de la loi du $1^{\mathrm{er}}$ janvier 1798 : recourant à la technique de la fiction juridique, le législateur fait comme si le nouveau libre africain était né sur le sol français.

26 S'agissant de l'article 18, Roger-Ducos précise qu'il s'applique pour l'avenir à l'« individu noir, né en Afrique ou dans les colonies étrangères, transféré dans les îles françaises ${ }^{23}$ »: affranchi par le sol français, il n'en relève pas moins de l'article 10 de la constitution, comme tout étranger ordinaire, pour accéder à la qualité de citoyen. Ces «noirs transférés » doivent être distingués des «noirs transportés, résidants et domiciliés dans nos colonies ", qui eux, grâce à l'article 15 de la résolution, relèvent des articles 8 et 9 de la constitution.

Quant aux conditions pour «jouir du droit de citoyen », d'âge ou de cens notamment, ce sont celles prévues par la constitution de l'an III, nonobstant des aménagements de détails dans les articles 19 et 20. L'article 14, qui offre aux noirs comme aux blancs un moyen de prouver leur âge en l'absence d'état-civil ne pose pas, lui non plus, de difficulté particulière.

Le législateur se sera ainsi beaucoup plus préoccupé de nationalité (rarement texte sous la I ${ }^{\text {ère }}$ République aura aussi clairement traité cette question) que de citoyenneté stricto sensu. Mais cette nationalité est de toute évidence pensée par rapport à la citoyenneté. La 
loi du $1^{\text {er }}$ janvier 1798 créé une situation complexe: il y a tous ceux qui, libres de naissance ou non, sont nés dans les colonies françaises et relèvent de l'article 8 de la constitution de l'an III, les Africains affranchis par le sol français jusqu'à l'entrée en vigueur de la loi qui sont régis par son article 15 , les étrangers ordinaires et après l'entrée en vigueur de la loi, les Africains et les esclaves créoles des colonies étrangères, qui relèvent de l'article 10 de la constitution.

Par rapport au décret du 16 pluviôse, il y a ainsi un double aménagement : d'une part, les nouveaux libres africains ne sont français par leur domicile que s'ils ont une activité, d'autre part, à l'avenir, les esclaves africains ou de colonies affranchis par le sol français seront considérés comme des étrangers.

Malgré une réelle volonté d'application de la loi du $1^{\mathrm{er}}$ janvier 1798 par le Directoire ${ }^{24}$, le texte sera rapidement rendu sans objet par la constitution de l'an VIII, qui met fin à l'assimilation juridique des colonies. Cette utilisation de l'articulation entre la citoyenneté et la nationalité comme outil au service du processus de civilisation n'en constitue pas moins une innovation fondamentale. Un arrêté du $1^{\text {er }}$ thermidor an VII (8 août 1799 ${ }^{25}$ de l'agent particulier du Directoire en Guyane, Burnel, chargé notamment d'appliquer cette loi, traduit d'une manière quelque peu caricaturale cet état d'esprit. Il oblige ainsi les «individus noirs ou de couleur " à être vêtus d'une manière regardée comme correcte dans les habitations les nonidis et décadis et lorsqu'ils se rendent notamment à Cayenne: "Considérant que la République en rendant à leurs droits imprescriptibles les malheureuses victimes de l'esclavage, a voulu, par cet acte magnanime, les attacher au corps social, et les rendre dignes du grand nom de Citoyen Français. Considérant qu'on ne peut trop se hâter de détruire l'espèce d'incurie et de mépris pour tous les usages de la civilisation, qui, jusqu'ici, ont caractérisé ces nouveaux enfants de la Liberté [...]. »

De fait, dans le discours républicain, la citoyenneté des nouveaux libres est fréquemment conçue comme une compensation, une réparation des horreurs de l'esclavage et de la traite. L'approche sera donc forcément différente s'il est question d'insérer des hommes libres dans le processus de civilisation.

\section{B. Quel apprentissage de la citoyenneté pour les Egyptiens et les Indiens de Guyane?}

32 L'année 1798 est doublement marquée par la mission civilisatrice : d'une part avec le début de l'expédition d'Egypte (1798-1801) et d'autre part s'agissant des Amérindiens du département colonial de la Guyane.

En effet, les instructions du Directoire à l'agent particulier Burnel ${ }^{26}$, accordent une importance particulière aux Amérindiens. Une politique est esquissée: "Il est surtout essentiel de s'occuper dans tous les cantons les moins peuplés, d'y retenir par de bons traitements et d'y attirer même dès lors qu'il sera possible les Nations Indigènes, peuples doux et hospitaliers, et qui ayant déjà quelques moyens d'industrie peuvent être encouragés à se former en peuplades et à se fixer au voisinage de français. » Il est essentiel de leur faire sentir « les bienfaits de la constitution. » Pour ce faire, le Directoire prône une politique de mariages mixtes entre blancs, noirs ou hommes de couleur et Amérindiens. Si l'on retrouve ici les idées de la "colonisation nouvelle", avec une civilisation par la cohabitation, pour le Directoire, on a affaire ici à des «nations 
indiennes » dans le sens le plus classique du terme, regardées comme indépendantes. Il s'agit de pratiquer une sorte de prosélytisme de la civilisation à leur égard, de les sensibiliser à l'organisation constitutionnelle, mais pas de la leur imposer.

L'approche est autre en Egypte, où le projet de transformer le territoire en colonie n'est assumé que lorsque Menou est général en chef de l'armée d'Orient, en 1800-1801. C'est pourtant Bonaparte qui va le plus loin dans la volonté d'initier les Egyptiens aux institutions représentatives: rapidement, en juillet 1798, il créé au Caire un diwan, instance consultative composée de notables nommés, qui sera le principal lieu de contact entre les Français et les élites égyptiennes. En septembre 1798, Bonaparte convoque un " diwan général ${ }^{27}$ » de l'ensemble de l'Egypte par un ordre du jour du 20 fructidor an VI (6 septembre 1798) : chaque province doit y envoyer une délégation de notables. C'est aux généraux de les désigner " parmi les gens qui ont le plus d'influence sur le peuple, et les plus distingués du pays par leurs lumières, leurs talents et la manière dont ils ont accueilli les Français; ils auront soin de ne nommer aucun de ceux qui se seraient ouvertement prononcés contre nous. » Pour Bonaparte, «Le but de la convocation du diwan général [...] est un essai pour accoutumer les notables d'Egypte à des idées d'assemblée et de gouvernement. " On discutera notamment de justice, d'héritage, de droits de propriété et de levée des impôts. Ainsi, les Français insisteront-ils pour qu'il y ait des scrutins écrits lors de la première réunion du diwan général le 7 octobre 1798. La révolte du Caire, le 21 octobre 1798 met fin à cette conception ambitieuse du diwan. Restauré en décembre 1798, le diwan aura une existence quelque peu tumultueuse, mais demeurera un interlocuteur indispensable. Les membres en seront toujours, de manière directe ou indirecte, nommés.

Quant au recrutement des magistrats, la volonté de réaliser une synthèse entre la conception révolutionnaire et l'islam est traduite dans un ordre du jour de Menou relatif à l'organisation de la justice du 10 vendémiaire an IX (2 octobre 1800) ${ }^{28}$ avec d'une part l'abolition de la vénalité de la magistrature, d'autre part l'introduction d'une condition de nationalité égyptienne, esquissée à l'occasion, pour pouvoir être nommé magistrat. La conception d'ensemble n'en est pas moins hostile aux minorités religieuses, coptes notamment.

Si l'esprit des dispositions gravitant autour de ce «moment 1798 » diffère grandement de ce que l'on trouvera par la suite, on n'en voit pas moins apparaitre plusieurs idées essentielles: une conception différenciée de la nationalité sur une base à la fois territoriale et personnelle, une nationalité précaire qui peut être facilement retirée, une initiation à la citoyenneté qui passe par la nomination de notables indigènes.

Il n'en demeure pas moins qu'une différence essentielle existe: comme le constate Eschasseriaux, « la constitution exclut les étrangers de la jouissance des droits politiques ${ }^{29}$ » ce qui rend nécessaire l'instauration d'une fiction de nationalité française pour les nouveaux libres africains ; or la constitution de l'an VIII restaure le principe de spécialité législative qui signifie qu'une loi doit, pour être applicable aux colonies, le spécifier par une disposition expresse, principe qui sera maintenu par la suite. Il permet que des nonFrançais, étrangers ou indigènes, jouissent de droits politiques. C'est cette expérience, fondamentale pour la suite, qui sera réalisée en Algérie, entre 1847 et 1870. 


\section{Une citoyenneté pour les résidents : Français, étrangers et indigènes 1847-1870} 27 avril 1848: c'est par le biais de la loi du 24 avril 1833 rétablissant l'égalité juridique entre libres de couleur et blancs que les nouveaux libres, les anciens affranchis, les natifs libres des établissements français de l'Inde, lesquels sont soumis à un droit civil mixte franco-indigène, et ceux des comptoirs du Sénégal se voient reconnaître la citoyenneté française. Tirant les conséquences de l'absence d'état civil, et du fait que les anciens esclaves, à cause de leur affranchissement, auront par contre un titre d'état-civil, le gouvernement provisoire, par l'article 6 d'une instruction du 27 avril 1848, considère que sont dispensés de toute preuve de naturalisation, et donc réputés Français, les « habitants indigènes » de l'Inde ou des comptoirs du Sénégal y justifiant d'une résidence de plus de 5 ans et y ayant leur principal établissement. Par contre, en Guyane, les peuples marrons constitués au Surinam et les Amérindiens sont dans une situation largement en dehors du droit: dans la continuité du siècle précédent, ils sont regardés comme des «peuples indépendants » qui se voient reconnaître une totale autonomie quant à leurs affaires internes sans avoir officiellement de territoire propre ${ }^{30}$. C'est à partir des années 1960 qu'ils deviendront des électeurs.

40 Si ces «peuples libres » représentent des populations minoritaires et numériquement modestes, il en va tout autrement des indigènes d'Algérie qui, par leur situation juridique originale, obligent les autorités françaises à rechercher une articulation entre citoyenneté et nationalité, avant tout pour attribuer des droits politiques locaux.

\section{A. Comment articuler nationalité et citoyenneté ?}

41 Dès les débuts de la présence française en Algérie, la situation diffère juridiquement de celle de la métropole sur deux points essentiels : d'une part, les étrangers résidents en Algérie y jouissent d'un statut plus favorable; d'autre part, s'ajoute une nouvelle catégorie du droit de la nationalité, l'indigène d'Algérie, juif ou surtout musulman, qui est «sujet français ». C'est un Janus bifrons juridique: dans son territoire d'origine, il appartient à une population soumise, supporte l'essentiel de la charge fiscale, et l'on cherche à s'approprier ses terres; émigré en terre d'islam, s'il souhaite et peut se prévaloir du statut de « sujet français ", grâce notamment à sa "nationalité algérienne ", il devient un agent de l'influence française, jouit d'un statut quasiment égal à celui, très favorable, des Occidentaux, échappe largement à l'impôt et, au pire, bénéficie du statut de musulman dans un pays musulman (le critère confessionnel est déterminant jusqu'à ce que l'empire ottoman adopte une loi sur la nationalité en 1869).

À cette différence qualitative s'ajoute une différence quantitative: si les indigènes musulmans sont largement majoritaires, les Français sont également minoritaires dans l'ensemble qu'ils forment avec les étrangers, les « Européens ». 

manière très restrictive : elle se transmet avant tout par la filiation paternelle, comme le nom de famille; les femmes étrangères y accèdent par le mariage ; les étrangers nés en France peuvent opter pour elle dans l'année qui suit leur majorité. Les étrangers peuvent également solliciter l'admission à domicile, qui leur permet de jouir des seuls droits civils français, ou encore, soumise à des conditions beaucoup plus strictes, la naturalisation, qui leur permet de jouir, en outre, des droits politiques, et donc, d'être admis à la qualité de citoyen français. Depuis 1814, sauf dérogation, l'étranger naturalisé ne peut être élu au parlement.

Mais jusqu'en 1848, il n'est guère possible d'exercer des droits politiques en Algérie. Les premiers textes esquissant des municipalités aux attributions très limitées, l'arrêté ministériel du $1^{\mathrm{er}}$ septembre 1834 et l'ordonnance du 15 avril 1845, prévoient la nomination de Français ou d'Européens et d'indigènes. Pourtant, dès 1846, les termes du débat sont posés: dans un projet de rapport au roi accompagnant un projet de loi facilitant la naturalisation des étrangers en Algérie, le ministère de la guerre expose les différentes solutions envisagées ${ }^{31}$. "Convient-il de naturaliser les étrangers européens? Est-il possible et politique de naturaliser les indigènes ? Est-il plus convenable enfin de créer une naturalisation spéciale qui, sans donner aux étrangers ou aux indigènes habitant ce pays le caractère de français, leur accorderait cependant une nationalité particulière, une nationalité algérienne? » S'agissant des indigènes musulmans, aucune naturalisation, ni collective ni individuelle, qu'elle soit française ou «algérienne » ne paraît envisageable: "ils sont tout ce qu'ils peuvent être; ils sont sujets français. Ils jouissent de tous les droits civils établis par le Koran "; ils « ne se préoccupent pas d'une nationalité nouvelle : la religion seule leur en fait une ", cette situation permet d'user « de moyens rigoureux encore nécessaires et que nous ne saurions employer envers des citoyens soit français, soit algériens. » Il en va de même pour les israélites indigènes. Dans les deux cas, il faut attendre qu'ils se soient civilisés par le biais de l'instruction.

la naturalisation algérienne, « une naturalisation spéciale jetterai le premier fondement d'un empire séparé de la France »; de plus "il faut de toute nécessité, dans l'intérêt même de la France, que l'élément français conserve la prédominance dans ce pays, et il la perdrait le jour où l'élément européen appelé à jouir de droits égaux se trouverait en majorité en Afrique ».

46 L'ordonnance royale du 28 septembre 1847 relative à l'organisation municipale en Algérie, qui ne s'applique qu'en territoire civil, parait représenter un compromis entre partisans et adversaires d'une naturalisation algérienne : des indigènes, dans la limite du $1 / 4$ des sièges, et des étrangers admis à domicile peuvent être, comme les Français, nommés conseillers municipaux.

47 Avec l'avènement du suffrage universel masculin et de la $\mathrm{II}^{\mathrm{e}}$ République en 1848, la représentation de l'Algérie à l'Assemblée nationale pose la question de la citoyenneté française d'une manière plus aiguë: dès sa proclamation aux colons de l'Algérie du 2 mars 1848, le gouvernement provisoire montre qu'il ne s'intéresse guère aux indigènes et qu'il est favorable à l'assimilation du territoire. Le décret du 5 mars 1848 relatif à l'élection au suffrage universel direct de l'Assemblée nationale, tout en prévoyant la représentation des colonies et de l'Algérie, réserve le droit d'être électeur et éligible aux seuls Français; l'instruction du gouvernement provisoire du 12 mars 1848 pour l'exécution en Algérie de ce décret confirme qu'il faut "être né ou naturalisé Français » pour pouvoir s'inscrire sur les listes électorales. L'exclusion des indigènes, dont la 
situation particulière en matière de nationalité n'a pas changé, est confirmée le 27 avril par le décret abolissant de l'esclavage.

Un arrêté du pouvoir exécutif du 16 août 1848 se situe quant à lui dans la continuité de la monarchie de Juillet : dans les communes, le régime électif est instauré. Les étrangers et les indigènes, sous conditions, sont électeurs et éligibles au conseil municipal, dans la limite $\mathrm{du} 1 / 3$ des sièges. Ils ne peuvent toujours pas être maires ou adjoints.

La constitution du 4 novembre 1848 confirme la participation de l'Algérie à l'élection des députés mais aussi, à la différence des colonies, à celle du Président de la République. Peu de temps après, un arrêté du pouvoir exécutif du 9 décembre transforme les territoires civils en départements, marquant ainsi la vocation du territoire à être assimilé à la métropole. La population française compte alors une quarantaine de milliers d'individus. Le département se voit assigner une vocation ethnique : il est le territoire où dominent les Européens et avant tout les Français. De fait, peu de temps après, un autre arrêté du pouvoir exécutif, daté du 16 décembre, réserve à ces derniers l'électorat et l'éligibilité dans des conseils généraux qui ne seront pas mis en place.

La II République, qui s'était fixé pour objectif de marcher dans « la voie du progrès et de la civilisation» (préambule, I), aura ainsi fait de la commune le lieu d'initiation à la citoyenneté française des élites étrangères et indigènes établies en territoire civil : c'est par le contact avec les Français qu'elles entreront progressivement dans la nationalité française. Mais, en réservant la participation aux élections nationales aux citoyens français établis en Algérie, elle a, tout en supprimant le suffrage censitaire, favorisé la formation d'une nouvelle aristocratie.

51 La constitution du 14 janvier 1852 confie au Sénat, en son article 27, le soin de régler par un sénatus-consulte « la constitution des colonies et de l'Algérie »; elle prive en tout état de cause ce territoire, tout comme les colonies, de députés par le biais de l'article $35:$ « Il y aura un député au corps législatif à raison de trente cinq mille électeurs. »

52 Le régime, encore formellement républicain, envisage immédiatement de s'engager dans la voie de la naturalisation algérienne. Le titre $1^{\mathrm{er}}$ du projet de sénatus-consulte de $1852^{32}$, qui ne sera jamais adopté, décrit clairement un système où très peu de choses distingueraient le Français de l'étranger: en Algérie, les Français jouissent des même droits civils qu'en France, mais l'étendue de leurs droits politiques est fixée par le président de la République ; l'étranger résidant en Algérie jouit de la plénitude des droits civils et est soumis intégralement à la loi française: une admission à domicile automatique ; si les conditions pour être naturalisé français sont les mêmes qu'en France, une naturalisation algérienne, une "citoyenneté algérienne", qui ne produit ses effets qu'en Algérie, après notamment 3 années de résidence continue, est créée. Quant aux indigènes, le texte prévoit simplement qu'ils sont régis par décret du président de la République. Le projet, qui n'a rien d'arabophile, démontre une volonté de limiter l'influence des Français d'Algérie, qui n'avaient voté oui qu'à $53 \%$ au plébiscite de $1851^{33}$, en s'appuyant sur les étrangers.

En terme de droits politiques, en plus de la suppression de la représentation au parlement, la nomination se substitue à l'élection. S'agissant des conseils municipaux, le système de 1848 est suspendu dès 1850. Le texte est formellement abrogé par décret du 8 juillet 1854, qui rétablit l'ordonnance royale de 1847. Un décret du 27 octobre 1858 institue des conseils généraux dont les membres, nommés, sont des « notables européens ou indigènes » : ce texte, adopté dans la phase la plus assimilationiste du Second Empire, 
où le ministre de l'Algérie et des colonies, le prince Jerôme Napoléon, dirige l'Algérie depuis Paris, ne s'en situe pas moins dans la continuité de l'ordonnance de 1847.

La politique du «royaume arabe » de Napoléon III (1861-1870) est certainement plus un projet de transformation de l'Algérie en colonie d'exploitation qu'un projet d'émancipation des indigènes. Ses ambitions démocratiques paraissent pour le moins modestes, avec une mission civilisatrice placée sous le patronage de l'armée et plus particulièrement des officiers des bureaux arabes. Elle n'en aura pas moins fait du statut des indigènes une question politique.

Avec le sénatus-consulte du 14 juillet 1865 «relatif à l'état des personnes et à la naturalisation en Algérie ${ }^{34}$ ", les réponses sont données aux questions posées en 1846. Faut-il créer une « naturalisation algérienne » et donc une « nationalité algérienne »? La réponse est non : on considère toujours que la naturalisation doit produire des effets aussi bien en Algérie qu'en métropole, qu'il s'agisse des étrangers ou des indigènes. Faut-il faciliter la naturalisation des étrangers? La réponse est oui : la durée de résidence demandée à l'étranger est de 3 ans, alors qu'en métropole, depuis 1849, il faut 10 ans de résidence après avoir été admis à domicile. Faut-il permettre aux indigènes de se faire naturaliser individuellement? La réponse est là encore oui : l'indigène, musulman ou israélite, peut demander à se faire naturaliser. Il suffit qu'il ait 21 ans. Toutefois, la solution retenue met fin à des pratiques qui permettaient à l'indigène d'obtenir plus facilement la qualité de Français : en s'appuyant sur l'article 9 du Code civil, 4 indigènes musulmans, 15 indigènes israélites et 6 étrangers nés en Algérie avaient opté pour la nationalité française par déclaration à la mairie d'Alger à l'époque de leur majorité ${ }^{35}$. Plus largement, le texte, élaboré par le Conseil d'Etat, est moins libéral que l'avant-projet ${ }^{36}$, œuvre du Premier Président la Cour impériale d'Alger, Pierrey, exclusivement consacré à la naturalisation. En effet, tout en libéralisant les conditions de naturalisation des étrangers ( 5 ans, 2 ans en cas de services importants), cet avant-projet confirme le bénéfice de l'article 9 du Code civil aux étrangers nés en Algérie et leur permet d'opter pour la qualité de Français. Or les dispositions applicables aux étrangers sont aussi applicables aux indigènes musulmans "qui réclament le bénéfice de la naturalisation ", mais ils conservent " leurs droits civils tels qu'ils sont réglés par la loi musulmane », sauf s'ils souhaitent formellement être soumis "à la loi civile française». Les israélites indigènes, qui sont déjà soumis à un droit mixte franco-indigène et dont la naturalisation collective est sollicitée, sont quant à eux « soumis, pour l'avenir, en toute matière, à la loi civile française. » Il s'agit de les placer, eux qui sont, « du point de vue de la nationalité », " sujets français » et non pas « citoyens français », dans une situation analogue à celle des admis à domicile. "Ils pourront acquérir la qualité de citoyen français » selon les mêmes modalités que les étrangers. S'il n'y a aucun doute quant au bénéfice de l'article 9 du Code civil pour les israélites, la rédaction est plus floue s'agissant des musulmans. Ce projet est rejeté par le garde des Sceaux Baroche ${ }^{37}$ : «Ce système fait aux Juifs une situation diamétralement opposée » à celle des Musulmans. «Je crains qu'on accuse ce système de contradiction et même d'injustice, les capitulations protègent les Juifs comme les Musulmans. » De ce fait, les indigènes musulmans et israélites doivent demeurer soumis à leur loi religieuse et ne peuvent qu'être soumis à la loi civile française dès lors qu'ils auront obtenu cette «faveur » qu'est la naturalisation individuelle, dont l'obtention est facilitée pour eux. On assiste ici à la naissance de la légitimation de l'infériorité de l'indigène par le fait qu'il bénéficie d'un «statut personnel », par sa non-soumission au 
code civil. Elle est en partie déterminée par la recherche d'un point d'équilibre entre les Juifs et les Musulmans.

Faut-il naturaliser collectivement les indigènes? Le texte affirme que les indigènes musulmans et israélites sont français et peuvent sur leur demande, accéder à la qualité de citoyen français. L'auteur de l'exposé des motifs et rapporteur au Conseil d'Etat, Flandin, affirme que l'on a affaire ici à la naturalisation collective réclamée par une partie des israélites et que la nationalité française est accordée au peuple arabe. Cette affirmation ne figurait pas dans l'avant-projet de Pierrey, mais ce dernier n'en considérait pas moins que l'indigène était français. La Cour d'Alger, dans un arrêt du 24 février $1862^{38}$, avait tranché une affaire relative à un israélite indigène, Enos, en ce sens, et la cour de Cassation avait confirmé cette solution dans un arrêt du 15 février $1864^{39}$, estimant que, pour les indigènes, « la qualité de Français pouvait seule [...] constituer la base de la règle de leur condition civile et sociale. » Pour les magistrats, cette affirmation n'est rien d'autre qu'un principe interprétatif, une solution relevant surtout de la technique juridique : dans un contexte de pluralisme juridique, il s'agit de déterminer quel est le statut que l'on applique à titre subsidiaire à l'indigène, le statut qu'on lui applique en l'absence de dispositions le visant directement. C'est une valorisation de l'indigène, de son statut de sujet français, mais une valorisation uniquement dans le silence du législateur, qui ne met pas fin à la distinction entre citoyen français et sujet français. La volonté du principal inspirateur de la politique du royaume arabe, Ismaÿl Urbain, de faire adopter un texte affirmant que l'indigène est français, des motifs de politique étrangère, n'en vont pas moins favoriser l'adoption de ces dispositions : elles consacrent une jurisprudence de la cour de cassation mais, dans l'ensemble, ne constituent ni une amélioration ni une aggravation du statut de l'indigène. Dans sa lettre à Pierrey, Baroche s'interrogeait ainsi sur la portée d'une naturalisation permettant de demeurer sous l'empire de la loi musulmane : «Les droits politiques en Algérie sont peu étendus, et déjà en leur qualité de sujets français les musulmans sont admis à siéger dans les Conseils généraux et à exercer certaines fonctions publiques. A la vérité, ils acquerraient le droit d'entrer dans les rangs de l'armée au titre de Français, mais déjà des corps spéciaux leurs sont ouverts et certains grades leurs sont réservés. » Le texte ne fera que s'adapter à cette situation. Les décrets d'application prévus ne doivent d'ailleurs porter, en plus de la naturalisation, que sur l'accès, limité, aux emplois publics civils et militaires. Une des seules modifications du projet de texte lors de son examen au sénat consistera à adopter une rédaction assurant que les indigènes pourraient être élus et non pas seulement nommés dans les conseils municipaux ou généraux, modification accompagnée d'une déclaration du ministre de l'intérieur, Rouher, assurant que les indigènes pourront être électeurs dans les communes.

Le sénatus-consulte du 14 juillet 1865 aura ainsi assuré une valorisation plus symbolique que juridique de l'indigène par rapport à l'étranger, lequel peut, lui aussi, accéder à la fonction publique militaire (légion étrangère) et être nommé conseiller municipal ou général. De plus, il échappe aux dispositions d'exceptions auxquelles sont soumis les indigènes et peut solliciter la protection consulaire.

Le décret du 27 décembre 1866 relatif à l'organisation municipale confirme cet état de fait. Il opère une forme de synthèse entre les principes de 1847 et ceux de 1848 : le maire et les adjoints sont nommés et doivent être " citoyens français ou naturalisés français ", à l'exception des adjoints indigènes; les étrangers et les indigènes, sous conditions, sont électeurs et éligibles au conseil municipal, dans la limite $d u 1 / 3$ des sièges. On aboutit à la 
formation de deux corps électoraux numériquement équivalents : 29078 Français et 30178 non-Français, dont 19078 musulmans et 8863 étrangers ${ }^{40}$.

C'est au corps législatif, du 7 au 9 mars 1870, qu'a lieu un débat important sur la citoyenneté $^{41}$ : apprenant que le gouvernement envisage, de manière assez vague, de faire participer les indigènes et les étrangers à l'élection de députés dont on va bientôt doter l'Algérie, le républicain Jules Favre et le député de droite Le Hon se lancent dans une offensive contre le projet. Le débat culmine dans un échange entre Emile Ollivier, chef du gouvernement et garde des Sceaux, et Jules Favre, le 9 mars. Ollivier fait valoir que l'Algérie doit avoir 35000 électeurs pour avoir des députés et n'en a que 29000 : «L'admission des indigènes, en augmentant le nombre des électeurs, justifierait mieux la demande des députés [...]. Le Gouvernement de l'Empereur considère qu'au nom de la France, il a des obligations sacrées vis-à-vis des indigènes, obligations que les colons oublient quelquefois. [...] Voilà pourquoi nous sommes préoccupés de donner à l'élément indigène l'occasion de se manifester aussi, de défendre ses droits et d'être dans cette terre d'Algérie, que nous voulons rendre une terre libre, un élément satisfait et non un élément opprimé. » Pour Jules Favre, si l'élément indigène était représenté, il se traduirait " par l'apparition dans cette enceinte d'un indigène qui serait nommé par ses nationaux et qui viendrait y défendre les principes qu'il défend sur son sol. Vous ne voudriez pas une pareille chose. » De plus, les indigènes représenteraient en réalité l'armée, à cause des territoires militaires. Un ordre du jour en faveur du régime civil est finalement adopté à l'unanimité.

Le décret du 11 juin 1870 instaurant l'élection des conseils généraux par le corps électoral municipal en territoire civil est vécu comme une provocation: il prévoit toujours la représentation des indigènes et des étrangers et réaffirme l'existence du territoire militaire.

61 Après la chute de l'Empire, le décret du gouvernement de la défense nationale $d u$ 24 octobre 1870 relatif à l'organisation politique de l'Algérie dote les Français d'Algérie de 6 députés ( 2 par département) mais maintient les dispositions relatives aux conseils municipaux et généraux. Le même jour, le décret de naturalisation collective des israélites indigènes d'Algérie, déjà largement acquise sous le Second Empire, ajoute 35000 nouveaux Français à une population de 90000 individus environ. En conséquence, les dispositions du sénatus-consulte de 1865 relatives aux israélites indigènes sont abrogées et celles leur réservant une représentation aux élections locales deviennent sans objet.

C'est le décret du gouvernement de la défense nationale du 28 décembre 1870 sur les conseils généraux, abrogeant le décret du 11 juin, qui, tout en se plaçant dans la continuité de 1848, rompt avec une conception de la citoyenneté locale algérienne associant à la participation des indigènes celle des étrangers : « Considérant que le décret du 11 juin 1870 qui a organisé l'élection des membres des conseils généraux en Algérie est en opposition avec les principes du droit public, puisqu'il confère les droits d'électeur et d'éligible en matière politique à d'autres qu'aux citoyens français ou naturalisés français ; considérant qu'il ne saurait y avoir, dans les trois départements de l'Algérie d'autre politique que la politique française; considérant, relativement à la différence qui existe entre le nombre de citoyens électeurs et le chiffre total de la population de ces départements de maintenir, au sein des conseils, les membres indigènes dont la présence a répondu par le passé aux exigences de cette situation particulière. » En conséquence, seuls les "citoyens français et naturalisés français" sont électeurs et éligibles. S'y 
ajoutent quelques assesseurs indigènes musulmans nommés. Ils seront élus à partir de 1908.

63 La loi du 5 avril 1884 sur l'organisation municipale et son décret d'application du 7 avril se substituent plus tardivement au décret de 1866 et mettent fin à l'électorat et à l'éligibilité des étrangers.

Le rétablissement de la République en 1870 s'est avant tout accompagné du rétablissement du système mis en place en 1848 , où les citoyens français se voyaient réserver le monopole de l'électorat aux élections nationales et dans les conseils généraux, mais où ils cohabitaient avec les étrangers et les indigènes aux élections municipales. Cependant, en 1870, on s'efforce désormais de justifier l'exclusion des indigènes, notamment par la souveraineté nationale. Dans ce cadre-là, ce qui vaut pour les indigènes vaut a fortiori pour les étrangers, alors même que ces derniers continueront à peser au sein de la population européenne, jusqu'à ce que la loi de 1889 sur la nationalité soit adoptée et produise ses effets. La valorisation symbolique de l'indigène par le sénatusconsulte de 1865 aura ainsi fini par porter.

Toutefois, au-delà des principes, les variations de conceptions peuvent avoir des contenus différents, selon la population représentée.

\section{B. Comment attribuer des droits politiques locaux ?}

S'agissant de l'organisation municipale, il y a trois types de systèmes : l'un reposant sur la nomination, régi par l'ordonnance de 1847 , le système mixte, avec un conseil élu et des maires et adjoints nommés, de 1866, et le système purement électif de 1848. Cette organisation municipale concerne ce qu'on appellera par la suite les « communes de plein exercice ", dont l'organisation est la plus proche de celle des communes de métropole, dans les centres de population européenne.

Dans l'ordonnance de 1847, qui sera rétablie de 1854 à 1866, seuls les Français de 25 ans peuvent être maire ou adjoints. Pour être nommé conseiller municipal, il faut être en principe Français ou étranger admis à domicile et âgé de 21 ans. La nomination des indigènes est quant à elle une exception: ils doivent représenter au moins $1 / 10$ de la population de la commune et leur nombre est limité au $1 / 1 / 4$ des membres du conseil.

Dans l'arrêté du 16 août 1848, les indigènes et les étrangers ne peuvent se voir attribuer plus $\mathrm{du} 1 / 3$ des sièges et ne peuvent être ni maire ni adjoints.

Sont électeurs les Français résidant depuis un an dans la commune et âgé de 21 ans.

Sont électeurs et éligibles les étrangers et les indigènes musulmans et israélites âgés de 21 ans qui sont :

- soit admis à domicile en Algérie ;

- soit propriétaire, soit concessionnaire dans la commune;

- ou y payant, depuis 6 mois au moins un loyer annuel de $600 \mathrm{f}$ pour location de terres ou maisons;

- ou une patente ou licence de 3eme classe, au minimum.

L'étranger doit en outre justifier d'une résidence de 2 ans en Algérie, dont 1 dans la commune.

Sont éligibles les Français âgés de 25 ans, domiciliés dans la commune depuis 1 an au moins et ceux qui, sans y résider, y seraient propriétaires d'immeuble depuis un an ou y 
paieraient, depuis la même époque, une patente de $3^{e}$ classe au minimum. Ces derniers ne peuvent représenter plus $\mathrm{du} 1 / 1 / 4$ des membres du conseil.

L'originalité de ce système est d' être organisé autour de deux critères : la nationalité, avec les deux catégories de non-Français qui sont cette fois placées sur le même plan, et la contribution à la « mise en valeur » du territoire civil avec les conditions de suffrage des non-Français et l'éligibilité de Français qui ne sont pas électeurs.

Dans le décret de 1866, les indigènes et les étrangers ne peuvent se voir attribuer plus du $1 / 3$ des sièges au conseil municipal.

Sont électeurs les Français âgés de 21 ans, domiciliés dans la commune depuis au moins un an, inscrits sur le rôle des impôts locaux.

Sont également électeurs les indigènes et les étrangers âgés de 25 ans ayant un an de domicile dans la commune. Ils doivent en outre se trouver dans une des situations suivantes :

- être propriétaire foncier ou fermier d'une propriété rurale ;

- exercer une profession, un commerce ou une industrie soumis à l'impôt de patentes ;

- être employé de l'Etat, du département ou de la commune ;

- être membre de la légion d'honneur, décoré d'une médaille militaire ou de la médaille d'honneur ou d'une médaille commémorative donnée ou autorisée par le gouvernement français ou d'une pension de retraite.

Les étrangers doivent en outre justifier de 3 ans de résidence en Algérie.

Sont éligibles les électeurs de 25 ans et, pour les indigènes et les étrangers, justifiant de 3 ans de domicile.

Peuvent être nommés maires et adjoints les Français de 25 ans, résidents, propriétaires ou chefs d'établissement en Algérie. Sont également nommés des adjoints indigènes là où la population musulmane est suffisamment nombreuse. Leur autorité «ne s'exerce que sur leurs coreligionnaires. »

Par rapport à l'arrêté du 16 août 1848 , le décret de 1866 prend toujours en compte la nationalité et la «mise en valeur ", mais d'une manière différente. D'une part, le texte tire les conséquences du sénatus-consulte de 1865 : les étrangers doivent justifier d'une durée de résidence qui est celle pour être naturalisé ; la valorisation symbolique de l'indigène se traduit par la création d'adjoints. D'autre part, si l'on retrouve le colon étranger et les notables indigènes, s'y ajoutent le fonctionnaire et le militaire. On voit ici se dessiner un figure assez proche de celle de l'« indigène évolué ", seul susceptible d'être naturalisé et seul susceptible d'être électeur parmi les colonisés, telle qu'on la verra se développer dans l'entre-deux-guerres. Mais ici, l'étranger est soumis aux mêmes conditions.

S'il y a une certaine continuité entre les conceptions républicaine et impériale de l'électorat communal, il en va autrement pour les conseils généraux. Alors que l'arrêté du 16 décembre 1848 réserve l'électorat et l'éligibilité aux Français, le Second Empire conçoit le conseil général algérien comme un prolongement de la commune : avec le décret du 27 octobre 1858, les conseillers généraux sont « choisis parmi les notables européens ou indigènes résidant dans la province ou y étant propriétaire ", avec le décret du 11 juin 1870, il est élu par le corps électoral municipal en territoire civil, nommé en territoire militaire. Toutefois les conditions d'éligibilité diffèrent légèrement. Si les conseillers à titre français se voient attribuer au moins $2 / 3$ des sièges et sont 
majoritairement élus, les conseillers musulmans, qui détiennent la majorité des sièges restants, sont majoritairement nommés.

Le décret du 28 septembre 1870 ne rétablit pas la situation de 1848 à l'identique. Si les Français ont le monopole de l'électorat, sur les 36 membres du conseil, il y 6 assesseurs indigènes musulmans nommés, de préférence parmi les «notables indigènes qui auront acquis des notions pratiques de la langue française afin qu'ils puissent, par eux-mêmes, se rendre compte de l'esprit des discussions et des intentions libératrices de la France à l'égard des populations musulmanes. » On voit ici apparaître la condition de connaissance de la langue française qui sera un leitmotiv des décrets sur la naturalisation des indigènes dans les colonies.

On a vu naître ici cet électorat local sans la citoyenneté française qui sera, dans le Second Empire colonial, la situation la plus courante là où les indigènes pourront voter. A cet égard, l'abandon du projet de " citoyenneté algérienne » et les débats de 1870 ont porté : on se refusera toujours à reconnaître officiellement une citoyenneté locale, une citoyenneté coloniale, qui existe pourtant dans la pratique. Seuls ceux qui, du point de vue de la nationalité, sont Français ou citoyens français, se verront reconnaître un monopole du titre de citoyen. Cette scission entre électorat et citoyenneté française ne fera que s'amplifier dans les premières années de la $\mathrm{III}^{\mathrm{e}}$ République, lorsque les dernières innovations auront lieu.

\section{Une citoyenneté pour les ressortissants de l'Empire colonial : Français et indigènes 1870-1898}

80 En 1870, les principales formes et techniques de hiérarchisation caractérisant la citoyenneté du Second Empire colonial sont déjà en place : suffrage universel, suffrage restreint, nomination. La légitimation de l'infériorité de l'indigène par le «maintien » de son statut personnel vient d'être inventée. Tout le paradoxe de la République rétablie est qu'elle va produire une hiérarchisation parmi les Français.

81 Quant aux élections nationales, on retrouve en effet les régimes de citoyenneté présents en 1848 : les Antilles, la Guyane, la Réunion, l'Algérie sont à nouveau représentées. Parmi les colonies nouvellement conquises où il $\mathrm{y}$ a des indigènes, seule la Cochinchine se verra dotée d'un siège de député en 1881 : les citoyens français ont toujours le monopole de la participation aux élections nationales. Si l'Inde française et le Sénégal retrouvent également leur représentation parlementaire, la situation y sera plus complexe, surtout en Inde dans un premier temps.

La tendance à établir une hiérarchie parmi les Français se manifeste immédiatement : le décret de naturalisation collective des israélites indigènes du 24 octobre 1870 (décret " Crémieux ») donne bientôt lieu à une interprétation restrictive. Les israélites indigènes ayant «mal voté » (républicain en l'occurrence), un décret du 7 octobre 1871 (décret « Lambrecht ») définit l'indigène israélite de manière restrictive afin d'exclure les juifs originaires de la Tunisie et du Maroc. L'effet du texte est limité à une durée précise : soit les israélites prouvent dans les vingt jours qui suivent sa promulgation qu'ils sont indigènes, soit ils sont radiés des listes électorales. Normalement, l'affaire aurait dû en rester là, mais il n'en sera rien : une nationalité d'origine spécifique, valable uniquement quant à l'inscription sur les listes électorales, continuera d'être appliquée par 
l'administration dans les années 1890, et sera approuvée par la cour de cassation en avril 1896 et en mai $1897^{42}$.

Il y a une autre naturalisation collective, aboutissement d'une christianisation engagée dès la fin du XVIII siècle par la London Missionary Society: les sujets du royaume des Pomaré (Tahiti et dépendances, protectorat depuis 1843) bénéficieront, quant à eux, de la citoyenneté française à partir de la loi d'annexion du 30 décembre 1880 ; ils sont déjà soumis au code civil depuis 1874 (il y a une réserve quant à la propriété foncière). Tous les originaires des archipels qui composent aujourd'hui la Polynésie française seront soumis à la loi française, à l'exception des Iles Sous le Vent et de celles de Rurutu et de Rimatara. Pendant toute la III République, les Etablissements français de l'Océanie (EFO) n'auront pas de représentant au parlement. Toutefois, de 1885 à 1903, les institutions locales y sont relativement démocratiques, avec un conseil général élu au suffrage universel qui vote le budget. Pendant toute cette période, l'administration appelle au vote tous les habitants des EFO, qu'ils en soient originaires ou qu'ils soient d'origine métropolitaine. Toutefois, en 1891, le Conseil d'Etat refuse de reconnaitre la citoyenneté d'indigènes originaires de certains archipels qui ne faisaient pas partie du royaume des Pomaré (Marquises, Gambier, Rapa ${ }^{43}$ ) au motif qu'ils n'ont pas fait l'objet d'une naturalisation collective, alors même qu'ils sont soumis au Code civil. La Haute assemblée, qui avait élaboré le sénatusconsulte de 1865, consacre ainsi un système proche de celui prôné par le Premier Président de la Cour d'Alger, sauf qu'il n'y a pas d'indigènes naturalisés conservant leur statut personnel « coutumier».

Les situations des israélites indigènes et des indigènes des EFO resteront toutefois marginales : plutôt que la naturalisation collective, la République préférera dans son Empire colonial tricoter un statut particulier aux minorités jouant un rôle d'intermédiaire, notamment économique.

Deux formes de hiérarchisation parmi les Français s'avéreront autrement influentes: s'agissant des natifs des établissements français de l'Inde (EFI), on instituera notamment le système du double collège aux élections locales tout en reconnaissant un droit de participer aux élections nationales distinct de la citoyenneté française ; avec la création des délégations financières algériennes, on instaurera pour la première fois un système de "représentation des intérêts » tout en reconnaissant une citoyenneté française amputée du droit de participer à une élection locale.

\section{A. La naissance d'une citoyenneté locale amplifiée en Inde française}

Les EFI font partie, avec les Antilles et la Réunion, de ces colonies qui envoient à la fois un député et un sénateur au parlement. Voter aux élections locales, c'est donc également désigner les membres du collège qui élira le sénateur, dans un contexte institutionnel où le poids du sénat est égal à celui de la chambre des députés.

Les natifs sont soumis à un droit civil mixte franco-indigène et relèvent, quant à la nationalité, du code civil. Ils peuvent renoncer à ce statut personnel sur simple déclaration. D'abord reconnu par la jurisprudence, ce droit est organisé par un décret du 21 septembre 1881. On appelle ceux qui ont opté les renonçants.

Dès le rétablissement de la République, les natifs sont traités comme étant pleinement citoyens français quant à l'élection du député: ils participent à son élection dans un collège unique, et leurs voix comptent autant que celles des Européens. Aux élections 
locales, par contre, dès 1872, est organisé un système de double collège, distinguant les Européens et descendants d'Européens (donc les métis), d'une part, auxquels la majorité est garantie, et les natifs d'autre part.

En 1883, la direction des colonies refuse aux renonçants le droit de voter dans le collège européen. Ce point de vue est invalidé par la Cour de cassation, par un arrêt du 6 mars $1883^{44}$. Un décret du 26 février 1884 met alors en place un système de triple collège, distinguant les Européens et descendants d'Européens, les renonçants et les natifs non-renonçants. Mais, à cause du statut de faiseurs de majorité que confère le texte aux renonçants, un décret du 10 septembre 1899 restaure un système de double collège, chacun élisant cette fois la moitié des membres des diverses assemblées locales. Les renonçants sont ventilés dans chaque collège: ceux qui sont suffisamment assimilés votent avec les Européens et descendants d'Européens, les autres avec les natifs nonrenonçants. Pour être considéré comme assimilé, le natif doit avoir renoncé à son statut personnel depuis quinze ans au moins et soit avoir obtenu un diplôme dans les facultés de l'Etat, soit avoir occupé pendant cinq ans au moins une fonction administrative ou judiciaire, soit avoir exercé un mandat électif pendant cinq ans au moins, soit avoir obtenu une décoration (médaille d'honneur ou décoration française) et justifier de la connaissance de la langue française. Les renonçants sont ainsi dans une situation inférieure aux Européens, et les natifs non-renonçants, quel que soit leur niveau de culture, dans une situation inférieure aux renonçants. Les critères sont ici nettement à tendance capacitaire, et favorisent dans la pratique les fonctionnaires renonçants.

Mais les natifs offrent également à la Cochinchine une petite fonction publique alphabétisée et maîtrisant le français. La colonie a une population française très modeste, de quelques milliers d'individus. Dans un arrêt du 3 janvier $1888^{45}$, relatif à l'inscription sur les listes électorales de natifs non-renonçants qui souhaitent participer à l'élection du député, la Cour de cassation donne naissance à une création paradoxale : les natifs nonrenonçants peuvent participer aux élections nationales dans leur territoire d'origine, au titre d'un droit électoral spécifique, mais, du fait de leur non-renonciation, ne sont pas des « citoyens français jouissants des droits civils et politiques en métropole et dans les autres colonies ", où ils ne peuvent en conséquence participer aux élections nationales. On peut donc participer aux élections nationales sans être citoyen français : on assiste ici à une large extension de cette citoyenneté locale née en Algérie, que l'on refuse toujours de qualifier de citoyenneté. On tentera d'appliquer cette jurisprudence aux originaires des communes de plein exercice du Sénégal (Dakar, Gorée, Saint-Louis, Rufisque) à partir du milieu des années 1900, mais à la fin du XIX e siècle, ils élisent leur député sans que leur droit ne soit contesté.

91 On a ici une anticipation de conceptions que l'on trouvera à la Libération et sous la IV République. En Algérie, par contre, les délégations financières seront une source d'inspiration dans les autres colonies, protectorats et pays sous mandat de la $\mathrm{III}^{\mathrm{e}}$ République.

\section{B. La naissance de la représentation des intérêts en Algérie}

92 La création des délégations financières algériennes par un décret du 23 août 1898 est l'aboutissement de tendances manifestes dès l'arrêté du 16 août 1848 sur les communes. De manière plus conjoncturelle, elle est une réponse au mouvement autonomiste et 
antisémite qui culmine en 1897-1898 et un moyen de limiter les revendications de représentation des indigènes au parlement en instituant un « parlement colonial ». 9 sièges sont attribués aux indigènes non-kabyles des territoires civils, lesquels sont élus par les conseillers municipaux à titre indigène des communes de plein exercice, élus par un corps électoral très réduit, et par les membres indigènes des commissions municipales des communes mixtes, nommés par le préfet ; 6 sièges sont attribués aux indigènes nonkabyles des territoires de commandement désignés par le gouverneur général ; 6 sièges sont attribués aux indigènes kabyles, qui forment une section spéciale, et qui sont élus par les chefs de villages de Kabylie.

Conçues pour être provisoires, les délégations financières dureront 45 ans. Elles serviront de modèle en Afrique du Nord et dans le reste de l'Empire. Elle traduisent également une rupture nette avec les conceptions antérieures: désormais, l'assemblée locale coloniale 
doit traduire la finalité économique que lui attribue la métropole, désormais l'électeur n'est plus un citoyen, mais le représentant d'un groupe d'intérêt. Mais c'est paradoxalement par cette tentative d'instauration d'une citoyenneté dépolitisée que prend véritablement naissance cette citoyenneté algérienne qu'on rejetait depuis 1846.

La longue genèse de la citoyenneté dans le Second Empire colonial aura ainsi été l'histoire d'un morcellement continu: dualité du droit de la nationalité, scission entre électorat local et citoyenneté française, éclatement de la citoyenneté française en groupes d'intérêts locaux. Les autorités françaises n'auront plus qu'à choisir dans ce répertoire de formes disponibles et instaurer la combinaison qui paraîtra la plus adéquate, le type de division qui paraîtra le plus judicieux.

La seule innovation qui aura lieu par la suite sous la IIIe République sera à certains égards un retour aux sources: les originaires musulmans des communes de plein exercice du Sénégal bénéficient d'un statut personnel limité. Ils participent à l'élection du député du Sénégal à la fin du XIX siècle sans que cela fasse l'objet de contestations particulières de la part des autorités françaises. Mais, à partir des années 1900, l'administration et la Cour de cassation tentent de les placer dans une situation analogue à celle des natifs nonrenonçants de l'Inde française et donc de ne leur reconnaître qu'une citoyenneté locale élargie. Cela a notamment pour conséquence de soumettre cette population qui compte de nombreux commerçants à la justice pénale réservée aux indigènes sujets français lorsqu'ils sont hors du territoire des communes.

Il s'en suivra une réaction politique vigoureuse des intéressés qui débouchera sur les lois «Diagne» du 19 octobre 1915 et surtout du 24 septembre 1916: les originaires des communes se voient reconnaître par la représentation nationale le bénéfice de la citoyenneté française tout en conservant leur statut personnel restreint parce qu'ils sont nés ou descendent de personnes nées dans les communes, autrement dit parce qu'une nationalité d'origine spécifique a été définie pour eux. Si l'homogénéité de la citoyenneté française dans son sens politique est préservée, il est clairement mis fin à la conjonction entre nationalité française et citoyenneté française. Sans ces lois, les choses se seraient probablement passées selon des modalités juridiques différentes en 1945 et en 1946.

Mais on retrouve ici des traces de la loi du $1^{\text {er }}$ janvier 1798, de l'avant-projet de sénatusconsulte de 1865 du Premier Président Pierrey et cette conviction que la commune est le lieu d'initiation à la citoyenneté : là encore, la période qui s'étend de 1798 à 1898 s'avère fondamentale.

\section{BIBLIOGRAPHIE}

Charles-Robert AGERON, Les Algériens musulmans et la France (1871-1919), Paris, PUF, 1968.

Charles-Robert AGERON, "L'évolution politique de l'Algérie sous le Second Empire ", dans CharlesRobert AGERON, De l'Algérie « française » à l'Algérie algérienne, Paris, Bouchêne, 2005, p. 97-134. 
David ANNOUSSAMY, L'intermède français en Inde. Secousses politiques et mutations juridiques, Paris, L'Harmattan, 2005.

Michel ANSKY, Les Juifs d'Algérie, du décret Crémieux à la Libération, Paris, éditions du Centre, 1950. Louis-Augustin BARRIERE, Le statut personnel des musulmans d'Algérie de 1834 à 1862, Dijon, EUD, 1993. Jacques BOUVERESSE, Un parlement colonial ? Les délégations financières algériennes (1898-1945). T. 1. L'institution et les hommes, Mont Saint-Aignan, Publications des Universités de Rouen et du Havre, 2008.

Patrice BRET, L'Egypte au temps de l'expédition de Bonaparte, 1798-1801, Paris, Hachette Littératures, 1998.

Jean-Luc CHAPPEY, «Révolution, régénération, civilisation : enjeux culturels des dynamiques politiques », dans Jean-Luc CHAPPEY, Bernard GAINOT, Guillaume MAZEAU, Frédéric RÉGENT, Pierre SERNA, Pour quoi faire la révolution, Marseille, Agone, 2012, p. 115-148.

Claude COLLOT, Les institutions de l'Algérie durant la période coloniale (1830-1962), Paris/Alger, CNRS/ OPU, 1987.

Bernard GAINOT, « La naissance des départements d'outre-mer. La loi du $1^{\mathrm{er}}$ janvier 1798 », Revue des Mascareignes, $\mathrm{n}^{\circ}$ 1, 1999, p. 51-74.

Jean-Marcel hURAULT, Français et Indiens en Guyane, Paris, UGE, coll. « 10/18 », 1972.

Wesley G. JoHnson, Naissance du Sénégal contemporain. Aux origines de la vie politique moderne (1900-1920), Paris, Karthala, 1991, trad. F. Manchuelle, (The emergence of Black Politics in Senegal: The struggle for Power in the Four Communes, Stanford, Stanford University Press, 1971).

Henry LauRens, L'expédition d'Egypte. 1798-1801, Paris, Seuil, 2e éd. 1997 (1ère éd., Armand Colin, 1989), coll. « Points »

Frédéric RÉGENT, Jean-François NIORT, Pierre SERNA (dir.), Les colonies, la Révolution française, la loi, Rennes, PUR, 2014.

Annie REY-GOLDZEIGUER, Le Royaume arabe. La politique algérienne de Napoléon III (1861-1870), Alger, SNED, 1977

Annie REY-GOLDZEIGUER, « Les plébiscites en Algérie sous le Second Empire », Revue Historique, vol. 229,1963 , p. 123-158.

Miranda Frances SPIELER, « The Legal Structure of Colonial Rule during the French Revolution », The William and Mary Quarterly, Third Series, vol. 66, No. 2 (Apr., 2009), p. 365-408.

Pierre-Yves toulLELAN, Bernard GILLE, Le mariage franco-tahitien. Histoire de Tahiti du XVIIIème siècle à nos jours, Tahiti, Polymages-Scoop, 1994.

Michel TROPER, Terminer la Révolution. La constitution de 1795, Paris, Fayard, 2006.

Yerri URBAN, L'indigène dans le droit colonial français (1865-1955), Paris, LGDJ, coll. « Fondation Varenne ", 2011.

Patrick WEIL, Qu'est-ce qu'un Français ? Histoire de la nationalité française depuis la Révolution, Paris, Gallimard, coll. « folio histoire », $20052^{\mathrm{e}}$ éd. (2002),

Recueils de textes législatifs et réglementaires

Jean Baptiste DUVERGIER, Collection complète des lois, décrets, ordonnances, règlements et avis du Conseil d'Etat. 
Charles-Louis PINSON DE MENERVILLE, Dictionnaire de la législation algérienne. Code annoté et manuel raisonné des lois, ordonnances, décrets, décisions et arrêtés publiés au Bulletin officiel des actes du gouvernement, t. 1, 1830-1860, Alger, 1867 ; t. 2, 1860-1866, Alger, 1866 et t. 3, 1866-1872, Alger, 1872.

\section{NOTES}

1. Sur la notion d'Empire voir notamment, sous l'angle de la théorie constitutionnelle et de la philosophie du droit, les actes du colloque organisé par Olivier BEAUD, «Peut-on penser juridiquement l'Empire comme forme politique?", Jus Politicum, n 14, juin 2015 (http:// juspoliticum.com/-No-14-.html); le numéro spécial de la revue de philosophie Astérion $\mathrm{n}^{\circ} 10$, 2012 sur « Empire et domination territoriale » (http://asterion.revues.org/2221) ; sous l'angle de la science politique, le numéro spécial de la revue Questions internationales, $\mathrm{n}^{\circ} 26$ (juilletaoût 2007) sur « Les empires».

2. Pour une réflexion plus théorique et juridique sur cette question, voir Yerri URBAN, «La citoyenneté dans l'Empire colonial français est-elle spécifique? », Jus Politicum, n 14, juin 2015, (http://juspoliticum.com/La-citoyennete-dans-l-empire.html).

3. Pierre LAMPUÉ, Législation coloniale. Licence $3^{e}$ année. 1944-1945, 1946-1947, Paris, Les Cours de droit, 1946.

4. Ibid., p. 388.

5. Ibid., p. 409.

6. Ibid., p. 27et suivantes.

7. Yerri URBAN, L'indigène dans le droit colonial français (1865-1955), Paris, LGDJ, 2011, collection «Fondation Varenne ».

8. Jean-Luc CHAPPEY, «Révolution, régénération, civilisation: enjeux culturels des dynamiques politiques », dans Jean-Luc CHAPPEY, Bernard GAINOT, Guillaume MAZEAU, Frédéric RÉGENT, Pierre SERNA, Pour quoi faire la révolution, Marseille, Agone, 2012, p. 115-148, p. 145.

9. Ibid., p. 134-135.

10. Ibid., p. 138-140.

11. Bernard GAINOT, «La naissance des départements d'outre-mer. La loi du $1^{\mathrm{er}}$ janvier1798 », Revue des Mascareignes, $\mathrm{n}^{\circ}$ 1, 1999, p. 51-74.

12. Pour les textes normatifs cités dans cet article, voir Jean Baptiste. DUVERGIER, Collection complète des lois, décrets, ordonnances, règlements et avis du Conseil d'Etat.

13. Jean-Luc CHAPPEY, «Raison et citoyenneté : les fondements culturels d'une distinction sociale et politique sous le Directoire ", dans Citoyen et citoyenneté sous la Révolution, actes du colloque de Vizille du 24-25 septembre 2005, Paris, Société des études robespierristes, 2006, p. 279-288.

14. Ibid., p. 281-282.

15. BNF, Le (38) 1593, Rapport et projet d'articles constitutionnels relatifs aux colonies présentés à la Convention nationale au nom de la Commission des Onze par Boissy d'Anglas, dans la séance du 17 thermidor an III (4 août 1795).

16. C'est moi qui souligne.

17. BNF, Le (43) 1475, Rapport fait par Eschassériaux aîné au nom de la Commission chargée de présenter les lois organiques de la Constitution dans les colonies, et les mesures de législation et de politique pour opérer leur rétablissement. $1^{\mathrm{er}}$ brumaire an VI (22 octobre 1797).

18. BNF, Le (45) 706, Rapport fait par Roger-Ducos, au nom d'une commission spéciale, sur la résolution du 28 brumaire dernier, relative à l'organisation de la Constitution dans les colonies. Séances des 25 et 26 frimaire de l'an VI (15-16 décembre 1797). Voir. aussi BNF, Le (45) 724, 
Réponse de Roger-Ducos aux objections faites contre la résolution relative à la mise en activité de la Constitution dans les colonies. Séance du 12 nivôse an VI ( $1^{\mathrm{er}}$ janvier 1798).

19. BNF, Le (45) 2154, Opinion de Dufay sur le titre III de la résolution soumise au Conseil des Anciens, concernant l'organisation de la Constitution dans les colonies.

20. BNF, Le (43) 1475, Rapport fait par Eschassériaux aîné..., op. cit.

21. BNF, Le (45) 706, Rapport fait par Roger-Ducos ... op. cit.

22. Roger-Ducos insiste beaucoup dans son rapport sur les règlements de culture.

23. Cet article est rédigé au futur, alors que l'article 15 est au présent.

24. Voir Frédéric RÉGENT, « Droit et pratique de la liberté générale en Guadeloupe (1794-1802) », dans Frédéric RÉGENT, Jean-François NIORT, Pierre SERNA (dir.), Les colonies, la Révolution française, la loi, Rennes, PUR, 2014, p. 125-145.

25. ANOM, C14/77, 235MIOM/49, Arrêté de l'agent particulier du Directoire exécutif Burnel, délégué à la Guyane française, $1^{\text {er }}$ thermidor an VII (19 juillet 1799).

26. ANOM, C14/77, 235MIOM/49, Instructions pour le citoyen Burnel, agent particulier du Gouvernement dans la Guyanne du 25 thermidor an VI (12 août 1798).

27. Patrice BRET, L'Egypte au temps de l'expédition de Bonaparte. 1798-1801, Paris, Hachette Littératures, 1998, p. 110 et suivantes ; Henry LAURENS, L'expédition d'Egypte. 1798-1801, Paris, Seuil, $2^{\mathrm{e}}$ éd. 1997 (1ère éd., Armand Colin, 1989), coll. « Points », p. 188-189, p. 203 et suivantes.

28. Yerri URBAN, «L'ordre du jour du 10 vendémiaire an IX (2 octobre 1800) relatif à l'organisation de la justice en Egypte : vers un nouveau droit colonial » dans Frédéric RÉGENT, Jean-François NIORT, Pierre SERNA (dir.), op. cit., p. 149-164.

29. BNF, Le (43) 1475, Rapport fait par Eschassériaux aîné..., op. cit.

30. Voir Yerri URBAN, «Le rattachement d'un peuple marron à la France. Les Boni, de la Guyane néerlandaise à la Guyane française (1836-1892) », Cahiers aixois d'histoire des droits de l'outre-mer français, à paraître.

31. ANOM, FM, F80/2043, Projet de rapport au roi, ministère de la guerre, 7 septembre 1846 ; voir Patrick WEIL, Qu'est-ce qu'un Français? Histoire de la nationalité française depuis la Révolution, Paris, Gallimard, coll. « folio histoire ", $20052^{\mathrm{e}}$ éd. (2002), p. 339 et suivantes.

32. Voir ANOM, FM F80/2043, le projet de sénatus-consulte organique de l'Algérie, 5 juillet 1852,

33. Voir Annie REY-GolzEIGUER, "Les plébiscites en Algérie sous le Second Empire", Revue Historique, vol. 229, 1963, p. 123-158, p. 148.

34. Pour les débats au Sénat, Voir le Moniteur, $1^{\text {er }}$ et 6 juillet 1865 ; Pour l'élaboration du texte, ANOM F80/2043.

35. Ibid., Lettre du Procureur général au Garde des Sceaux, Alger, 7 février 1865,

36. Avant-projet de sénatus-consulte sur la naturalisation en Algérie, 19 mai 1865, ibid.; Lettre du Premier Président de la Cour d'Alger au Gouverneur Général, 17 mars 1865, ibid.

37. Copie d'une lettre adressée par M. le Garde des Sceaux à M. le Premier Président de la Cour Impériale d'Alger le12 avril 1865, ibid.

38. Cour impériale d'Alger, 24 février 1862, Journal de Robe, 1862, p. 86 ; Recueil Dalloz, 1862, II, p. 179.

39. Cour de Cassation, 15 février 1864, Recueil Dalloz, 1864, I, p. 67 ; Recueil Sirey, 1864, I, p. 114.

40. Charles-Robert AGERON, "L'évolution politique de l'Algérie sous le Second Empire ", dans Charles-Robert AGERON, De l'Algérie "française» à l'Algérie algérienne, Paris, Bouchêne, 2005, p. 97-134, p. 119.

41. Moniteur, 26 février, 8,9 et 10 mars 1870 .

42. Arrêts des 18, 22 et 27 avril 1896, 3 et 24 mai 1897, Recueil Dalloz, 1896, I, p. 356 ; Revue algérienne et tunisienne de doctrine, législation et jurisprudence, 1896, II, p. 100, p. 161 et 1897, II, p. 225 ; Recueil Sirey, 1896, I, p.241et 1897, I, p.97. La Cour de Cassation confirmera sa jurisprudence le 12 janvier 1939 suite à des radiations des listes électorales effectuées par un 
maire antisémite. Un décret modificatif du 16 janvier 1939 atténuera alors beaucoup la portée du texte. Par ailleurs, le bénéfice du décret Crémieux est refusé aux israélites originaires de territoires annexés à l'Algérie après 1870, notamment des oasis du M'zab, annexées à l'Algérie en 1882.

43. CE, 24 avril 1891, Lebon, p. 300.

44. Cour de Cassation, civ. rejet, 6 mars 1883, Recueil Sirey, 1883, I, p. 379 ; Recueil Dalloz, 1883, I, p. 308

45. Cour de Cassation, civ., 3 janvier 1888, Recueil Sirey, 1888, I, p. 228.

46. Jacques BOUVERESSE, Un parlement colonial ? Les délégations financières algériennes (1898-1945). T. 1. L'institutions et les hommes, Mont Saint-Aignan, Publications des Universités de Rouen et du Havre, 2008, p. 75.

47. Le texte sera modifié en 1900 pour viser expressément cette catégorie après un arrêt de la Cour de Cassation du 24 juillet 1899. Revue algérienne et tunisienne de doctrine, législation et jurisprudence, 1899, II, p. 337.

48. Ce qui exclut ceux qui sont nés de parents indigènes.

\section{INDEX}

Mots-clés : droit, citoyenneté, nationalité, indigène, empire colonial français, Algérie, colonies, expédition d'Egypte, révolutions françaises, abolitions de l'esclavage

Keywords : law, citizenship, nationality, native, French Colonial Empire, Algeria and colonies, expedition to Egypt, French revolutions, abolitions of slavery

\section{AUTEUR}

\section{YERRI URBAN}

Maître de conférences en droit public

Université des Antilles, Faculté de droit de la Martinique

Centre de Recherche sur les Pouvoirs Locaux dans la Caraïbe (CRPLC, UMR 8053)

Chercheur associé IHRF 